\title{
Correction to: A review of phosphorus recovery from different thermal treatment products of sewage sludge
}

\author{
Xiangdong Meng ${ }^{1} \cdot$ Qunxing Huang ${ }^{1}$ (I) Jie Xu ${ }^{1} \cdot$ Huaping Gao ${ }^{2} \cdot$ Jianhua Yan $^{1}$
}

Published online: 29 January 2020

(c) Zhejiang University Press 2020

\section{Correction to: \\ Waste Disposal \& Sustainable Energy (2019) 1:99-115 \\ https://doi.org/10.1007/s42768-019-00007-x}

Figure 1 was mislabeled. Please find Fig. 1 with the correct labelling below. The authors would like to apologize for any inconvenience caused to the readers by these changes

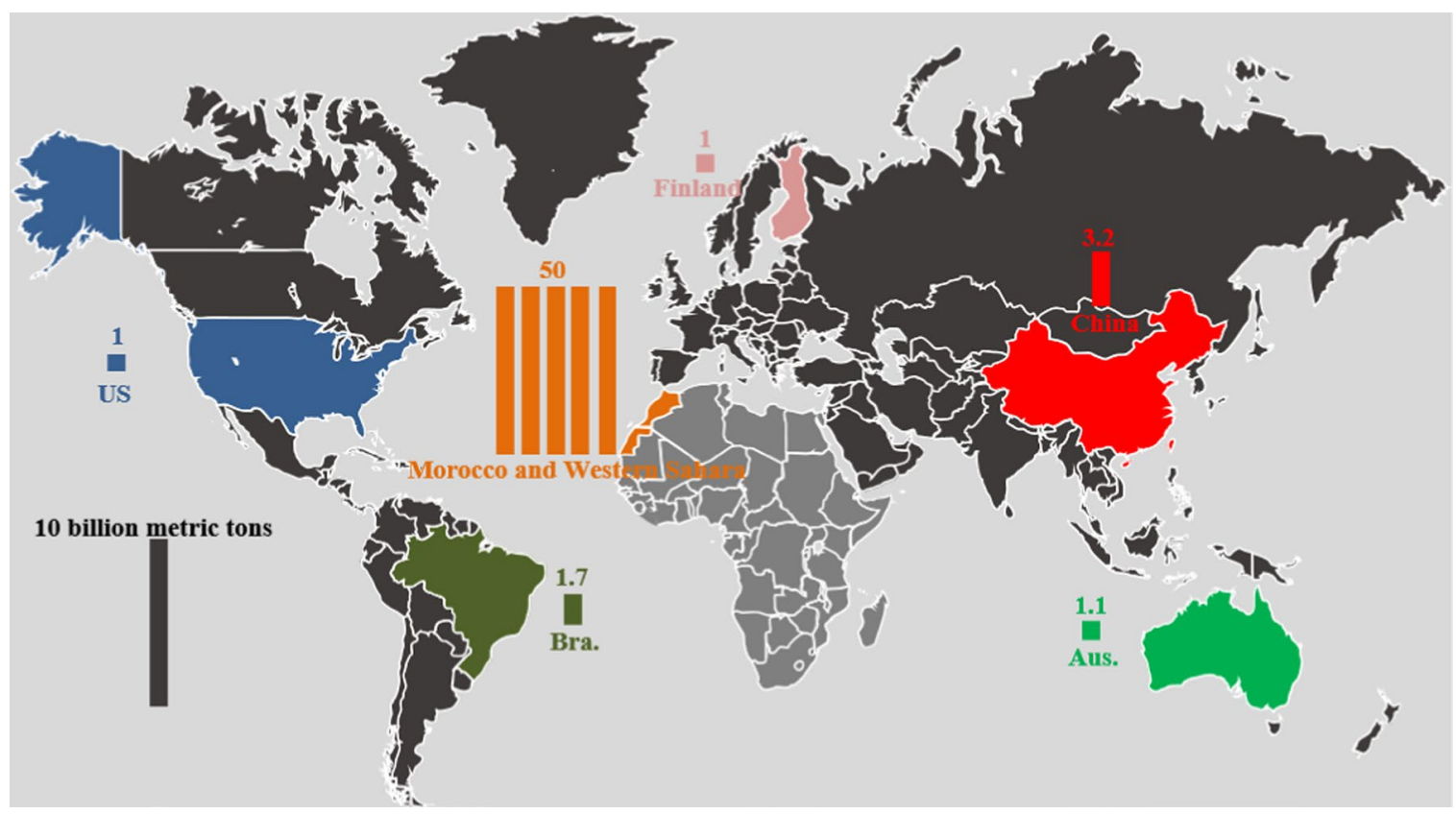

Fig. 1 The phosphate rock reserves of China and some other main countries

The original article can be found online at https://doi.org/10.1007/ s42768-019-00007-x.

\section{Qunxing Huang}

hqx@zju.edu.cn

1 State Key Laboratory of Clean Energy Utilization, Institute for Thermal Power Engineering, Zhejiang University, 38 Zheda Road, Hangzhou 310027, China
Publisher's Note Springer Nature remains neutral with regard to jurisdictional claims in published maps and institutional affiliations.

College of Environmental Science and Engineering, Kunming University of Science and Technology, Kunming 650093, China 